\title{
Review on the Molecular Tools for the Understanding of the Epidemiology of Animal Trypanosomosis in West Africa
}

\author{
G Duvallet/ ${ }^{+}$, S de La Rocque*, JM Reifenberg, P Solano*, T Lefrançois*, \\ JF Michel*, Z Bengaly*, I Sidibe*, D Cuisance, G Cuny**
}

\author{
CIRAD-EMVT, B.P. 5035, 34032 Montpellier Cedex 1, France *CIRDES, 01 B.P. 454, Bobo-Dioulasso, \\ Burkina Faso **ORSTOM, B.P. 5045, 34032 Montpellier Cedex 1, France
}

The epidemiology of animal trypanosomosis around Bobo-Dioulasso (Burkina Faso, West Africa) benefited a lot in the last years from the progress of molecular tools. The two most used molecular techniques were the polymerase chain reaction for the diagnosis of the disease in cattle and the characterization of the trypanosomes in the host and the vector on one hand, and the microsatellite DNA polymorphism in tsetse flies to study the intraspecific genetic variability of the vector on the other hand. The results obtained in the Sideradougou area during a recent two year survey with these techniques, associated with many other georeferenced informations concerning vector and cattle distribution, natural environment, landuse, ground occupation, livestock management, were combined in a Geographical Information System. This new approach of a complex pathogenic system led to a better evaluation of the risk of trypanosome transmission.

Key words: African animal trypanosomosis - epidemiology - polymerase chain reaction- microsatellite DNA Glossina - Trypanosoma sp.

Animal trypanosomosis represents a serious problem in most of Africa and also in certain zones of South America and Asia. The control methods currently in use require a good knowledge of the epidemiology of the disease for a better effectiveness.

The epidemiology of animal trypanosomosis around Bobo-Dioulasso (Burkina Faso) benefited a lot in the last years from the progress of molecular biology tools. The most employed techniques were (1) the polymerase chain reaction (PCR) for the diagnosis of the disease in cattle and the characterization of the trypanosomes in the host and the vectors; (2) the microsatellite DNA polymorphism in tsetse flies for the study of the intraspecific genetic variability of the vectors.

The PCR combines the advantages of a greater sensibility than the parasitological or immunological techniques with the possibility of differentiating trypanosomes which have a similar morphology but a very different economic impact.

\footnotetext{
This work was funded by CIRAD-EMVT (Action thématique programmée 'Santé-Environnement'), CNRS (Programme interdisciplinaire 'Environnement, Vies et Societes'), AUPELF-UREF (LAF no. X/7.10.02/ 4581-306) and CIRDES.

${ }^{+}$Corresponding author. Fax: +33-4-6759.3797. E-mail: duvallet@cirad.fr

Received 12 November 1998

Accepted 19 January 1999
}

The study of the microsatellite DNA polymorphism in tsetse flies appears to be of prime importance to assess the consequences of intraspecific genetic variability on the epidemiology of trypanosomosis.

All the results obtained in the Sideradougou area during a recent two year survey with these techniques, associated with many other georeferenced information concerning vector and cattle distribution, natural environment, landuse, livestock management, were combined in a Geographical Information System (GIS). This new approach of a complex pathogenic system must lead to a better evaluation of the risk of trypanosome transmission.

\section{MATERIALS AND METHODS}

Area - Sideradougou area is a pastoral zone situated in the southwestern part of Burkina Faso, where a multidisciplinary work aims to identify the most important factors determining the presence of tsetse flies which transmit the trypanosomes to cattle (de La Rocque \& Cuisance 1997). It lies in the south sudanian savannah zone $\left(4^{\circ} 20^{\prime} \mathrm{W}\right.$, $\left.10^{\circ} 55^{\prime} \mathrm{N}\right)$. More than $120 \mathrm{~km}$ of forest galleries were prospected in 1996 and 1997 for the catching of tsetse flies with biconical (Challier \& Laveissiere 1973) traps.

Tsetse flies - A total of 2,211 non teneral Glossina tachinoides and G. palpalis gambiensis were dissected among 4,357 captured flies. The instruments of dissection were carefully cleaned between 
each organ and each fly. After microscopic examination, the positive organs were placed in a single Eppendorf tube containing $50 \mu \mathrm{l}$ of sterile distilled water.

When the midgut of the flies contained enough blood residues, it was crushed on Whatman paper. The analysis of the tsetse blood meals was performed at CIRDES with an Elisa technique (Kabore et al. 1994).

Cattle - In 1996 and 1997, 120 cases of infection in cattle were identified in sentinel herds regularly checked for trypanosome infection by classical diagnosis methods involving buffy-coat examination (Murray et al. 1977) and thin blood smears. All the infected animals and the animals with a haematocrit value under $25 \%$ were submitted to PCR using a buffy-coat sample.

An exhaustive census of all the cattle present in the area has been recently accomplished and more than 1,000 cattle have been sampled out of 15,000 for a fair evaluation of the prevalence. The PCR has been used for the characterization of the trypanosomes in cattle.

$P C R$ - The PCR has been performed at CIRDES following a protocol derived from Penchenier et al. (1996). Details of the protocol are in Lefrançois et al. (1998).

The primers used were: Trypanosoma congolense savannah type: IL 0344-0345 (Majiwa et al. 1993), T. congolense riverine-forest type TCF 1,2 (Masiga et al. 1992), T. vivax VOL 1,2 (Dickin \& Gibson 1989), T. simiae TSM 1,2 (Masiga et al. 1992), and T. brucei s.l. TBR 1,2 (Moser et al. 1989).

Samples which gave negative results were systematically subjected to a new amplification reaction for 35 or 40 cycles, and if still negative, were DNA-extracted and submitted to an amplification reaction.

Each amplification was done in duplicate to ensure reproducibility, and a positive control (reference DNA of each type of trypanosome) and a negative control (without DNA) were added in each PCR assay.

Microsatellite markers - Microsatellite markers have been developed for G. p. gambiensis at ORSTOM lab in Montpellier (Solano et al. 1997). Three loci have been identified and showed size polymorphisms for insectarium samples. These markers have now been used for the characterization of tsetse flies populations of West Africa.

$G I S$ - The Sideradougou survey aimed at identifying factors in order to anticipate distribution and abundance of G. p. gambiensis and $G$. tachinoides in an area covering more than 1,000 $\mathrm{km}^{2}$ (de La Rocque 1997).
The study combined field survey and high resolution remote sensing data (SPOT images). The following different layers of information (all georeferenced) have been entered into a GIS: entomology ( 1 trap every $100 \mathrm{~m}$ along a $120 \mathrm{~km}$ hydrographic network), parasitology (standard methods and PCR results) from vector and cattle (sentinel herds), natural environment (70 parameters concerning vegetation, waterstreams and frequency of use), valley-type landuse, ground occupation and its dynamics (agricultural fragmentation), cattle distribution (exhaustive census, producer' typology), and the different pastoralist customs (livestock range management, drinking places). All the details are in de La Rocque (1997).

\section{PCR}

\section{RESULTS}

In tsetse flies - Among the 2,211 non teneral $G$. tachinoides and G. p. gambiensis dissected, the classical parasitological techniques gave the following results: (1) total infection rate: $14.6 \%$ in $G$. tachinoides, $12.1 \%$ in G. p. gambiensis (not statistically different); (2) Nannomonas type infection (proboscis + midgut): $13.6 \%$ in G. tachinoides, $7.4 \%$ in G. p. gambiensis (not different); (3) immature infection (midgut alone): $39 \%$ in $G$. tachinoides and $68.6 \%$ in G. p. gambiensis (statistically different); (4) Duttonnella type infection (proboscis alone): $45.8 \%$ in G. tachinoides and $21.5 \%$ in G. p. gambiensis (statistically different).

A total of 298 positive flies were submitted to PCR and the comparative results were the following:

- $72.7 \%$ of Nannomonas type infection could be characterized by PCR with: (1) $54.5 \%$ confirmed as Nannomonas (with $21.2 \%$ of mixed infections); (2) $15.2 \%$ identified as T. vivax; (3) $3 \%$ identified as mixed T. vivax/brucei.

- $15.8 \%$ of immature infections only could be characterized with PCR with: (1) $11.2 \%$ identified as $T$. congolense savannah type; (2) $3.3 \%$ identified as $T$. congolense forest type; (3) $3.9 \%$ identified as T. brucei.

- $87.9 \%$ of Duttonnella type infection could be characterized with PCR with $86 \%$ confirmed as $T$. vivax.

- T. simiae has not been identified during this survey.

In cattle - Among the 120 cases of infection identified in cattle, $90 \%$ could be characterized by PCR. It is important to note that $50 \%$ of parasitologically negative animals with a haematocrit value under $25 \%$ were identified as positive with PCR.

Among all the PCR positive animals: $63.3 \%$ were positive for $T$. congolense savannah type; $2.5 \%$ were positive for $T$. congolense forest type, 
$40 \%$ were positive for $T$. vivax; $9.2 \%$ were positive for $T$. brucei; $14.2 \%$ had mixed infection.

T. congolense riverine forest type was found only in three parasitologically negative animals with a haematocrit under $25 \%$. One of them had $T$. congolense forest type alone, and the other two had both types of $T$. congolense.

Bloodmeal analyses - A total of 233 midgut residues were analyzed for bloodmeal origin. Among all the results (Lefrancois et al. 1998) comparing tsetse species, sex and geographic position in the area, we retain here that (1) bloodmeals on ruminants were more frequent in G. tachinoides $(46.3 \%)$ than in G. p. gambiensis $(19.3 \%)$; (2) on the opposite, bloodmeals on reptiles were more frequent in G. p. gambiensis; (3) bloodmeals on reptiles were more frequent in males than in females, and in the western part of the area than in the eastern part.

Microsatellite markers - The study of the microsatellite DNA polymorphism of the G. $p$. gambiensis caught in the area showed at least two genetically different populations on the same hydrographic network. It is, to our knowledge, the first demonstration of a genetic variability of tsetse flies on a short distance $(13 \mathrm{~km})$. These two populations seem to be adapted to two different ecoepidemiological situations. These results are still being evaluated (Solano 1998).

\section{GIS}

The association of all the layers of information into a GIS led to a classification of favorable biotopes.

For example, G. tachinoides was more abundant in large and open forest galleries, and G. $p$. gambiensis more abundant in dense and closed galleries. G. tachinoides was more abundant in sites frequented by man and domestic animals (pigs, goats and sheep); G. p. gambiensis in sites frequented by cattle or wild antelopes. Many other parameters have been taken into account to analyze the spacial differences in vector localisation, type of trypanosome infection and hosts (de La Rocque 1997).

To briefly summarize the results, we could say that two different situations at least have been identified in the Sideradougou area for the G. $p$. gambiensis (de La Rocque 1997, Solano 1998):

- the Nyarafo situation in the western part with (1) high proportion of tsetse bloodmeals on reptiles; (2) high total infection rate of tsetse flies; (3) many cases of infection not identified by PCR with the primers used; (4) high infection rate of midgut.

- the Yeguere situation in the eastern part with (1) high proportion of tsetse bloodmeals on ruminants; (2) low total infection rates; (3) high infection rate of proboscis identified as T. vivax by PCR.

The microsatellite DNA markers have shown that these two populations of G. p. gambiensis were genetically different.

\section{DISCUSSION}

Molecular tools for the diagnosis and the epidemiology of animal trypanosomosis have been introduced several years ago at CIRDES (Duvallet \& Toure 1994, Reifenberg 1996, Reifenberg et al. 1997b). At the beginning, because of its cost, the PCR was limited to epidemiological studies in situations well known with classical methods. Now, with the decrease in the price of reagents and the possibility to use very low volumes and to run many samples at a time, the PCR can be envisaged as a diagnosis tool.

The high sensitivity of the PCR is illustrated in the Sideradougou survey by the fact that $90 \%$ of parasitologically infected and $50 \%$ of parasitologically negative animals (with classical tests) but with a haematocrite value under $25 \%$ were diagnosed as positive. T. simiae has not been identified in the Sideradougou area during this survey, but had been reported from other parts of Burkina Faso (Solano et al. 1996, Reifenberg et al. 1997a).

The PCR also made it possible to detect mixed infections and to characterize some of the immature infections. It is important to note that up to $45.5 \%$ of the presumed (classical parasitological tests) Nannomonas infections in tsetse flies were identified by PCR as T. vivax, T. brucei infections or were not identified.

Majiwa et al. (1994) already reported positive PCR results on $12.5 \%$ antigenemic but aparasitaemic animals.

The correlation between the low identification rate by PCR in the midgut infection (even after DNA extraction), the higher proportion of reptile bloodmeals especially for G. p. gambiensis, led us to hypothetise that the midgut infections came from reptile trypanosomes. Furthermore when bloodmeal analysis could be conducted on PCR non-identified midgut infected flies, $75 \%$ were from a reptile origin (Lefrançois et al. 1998).

The study of the genetic variability of the tsetse flies using microsatellite DNA polymorphism markers is still in progress at CIRDES (Solano 1998).

The integration of PCR results (characterization of the parasites), with bloodmeal origins, microsatellite markers, and many different environmental factors led to the identification of different eco-epidemiological situations. This new approach of a complex pathogenic system led to a 
better evaluation of the risk of trypanosome transmission.

\section{ACKNOWLEDGMENTS}

To Dr SM Toure, Director general, and all the technical staff of CIRDES.

\section{REFERENCES}

Challier A, Laveissiere C 1973. Un nouveau piege pour la capture des glossines: description et essais sur le terrain. Cahiers ORSTOM, serie Entomol medicale et Parasitol 11: 251-262.

De La Rocque S, Cuisance D 1997. Facteurs discriminants de la presence de glossines au Burkina Faso. Interet dans la prevision du risque de trypanosomoses, p. 31-32. In Proceedings of the International Symposium on Veterinary Epidemiology and Economics, 8-11 July, Paris, France. Epidemiol Sante anim no. special.

De La Rocque S 1997. Identification des Facteurs Discriminants Majeurs de la Presence des Glossines dans une Zone Agropastorale du Burkina Faso. Interet pour la Prevision du Risque Trypanosomien, PhD Thesis, Univ. Montpellier II, France, 201 pp.

Dickin SK, Gibson WC 1989. Hybridation with a repetitive DNA probe reveals the presence of small chromosomes in Trypanosoma vivax. Mol Biochem Parasitol 33: 135-142.

Duvallet G, Toure SM 1994. Transfert de nouveaux outils biotechnologiques au CIRDES pour une meilleure connaissance des trypanosomoses animales et de leur epidemiologie. Tropicultura 12: 155-156.

Kabore I, Amsler-Delafosse S, Bauer B, Staak C, Clausen P 1994. Analyse des repas de sang de mouches tsetse pour une contribution aux etudes epidemiologiques des trypanosomoses africaines. 4eme Congres de la SOAP, Ouagadougou, Burkina Faso.

Lefrançois T, Solano P, de La Rocque S, Bengaly Z, Reifenberg JM, Kabore I, Cuisance D, 1998. New epidemiological data on Animal Trypanosomosis by molecular analysis in the pastoral zone of Sideradougou, Burkina Faso. Mol Ecol 7:897-904.

Majiwa PAO, Maina M, Waitumbi JN, Mihok S, Zweygarth E 1993. Trypanosoma (Nannomonas) congolense: molecular characterization of a new genotype from Tsavo, Kenya. Parasitology 106: 151162.

Majiwa PAO, Thatthi R, Moloo SK, Nyeko JHP, Otieno
LH, Maloo S 1994. Detection of trypanosome infections in the saliva of tsetse flies and buffy-coat samples from antigenemic but aparasitaemic cattle. Parasitology 108: 313-322.

Masiga DK, Smyth AJ, Hayes P, Bromidge TJ, Gibson WC 1992. Sensitive detection of trypanosomes in tsetse flies by DNA amplification. Int J Parasitol 22: 909-918.

Moser DR, Cook GA, Ochs DE, Bailey C, McKane MR, Donelson JE 1989. Detection of Trypanosoma congolense and T. brucei subspecies by DNA amlification using the Polymerase Chain Reaction. Parasitology 99: 57-66.

Murray M, Murray PK, McIntyre WIM 1977. An improved parasitological technique for the diagnosis of African trypanosomiasis. Trans $R$ Soc Trop Med Hyg 71: 325-326.

Penchenier L, Dumas V, Grebaut P, Reifenberg JM, Cuny G 1996. Improvement of blood and fly gut processing for PCR diagnosis of trypanosomosis. Parasite 4: 387-389.

Reifenberg JM 1996. Etude des Relations Parasites-hotes dans l'Epidemiologie Moleculaire des Trypanosomoses Bovines au Burkina Faso, PhD Thesis, Univ. Montpellier II, France, 151 pp.

Reifenberg JM, Solano P, Bauer B, Kabore I, Cuny G, Duvallet G, Cuisance D 1997a. Apport de la technique PCR pour une meilleure comprehension de l'epizootiologie des trypanosomoses bovines: exemples de la zone pastorale de Yalle au Burkina Faso. Rev Elev Med vet Pays trop 50: 14-22.

Reifenberg JM, Solano P, Duvallet G, Cuisance D, Simpore J, Cuny G 1997b. Molecular characterization of trypanosome isolates from naturally infected domestic animals in Burkina Faso. Vet Parasitol 71: 251-262.

Solano P 1998. Importance Epidemiologique de la Variabilite Genetique des Populations de Glossines. Cas de Glossina palpalis en Afrique de l'Ouest, $\mathrm{PhD}$ Thesis, Univ. Montpellier II, France, en preparation.

Solano P, Duvallet G, Dumas V, Cuisance D, Cuny G 1997. Microsatellite markers for genetic population studies in Glossina palpalis (Diptera:Glossinidae). Acta Trop 65: 175-180.

Solano P, Reifenberg JM, Amsler-Delafosse S, Kabore I, Cuisance D, Duvallet G 1996. Trypanosome characterization by polymerase chain reaction in Glossina palpalis gambiensis and G. tachinoides from Burkina Faso. Med Vet Entomol 10: 354-358. 